\title{
THIAMINE BIOSYNTHESIS GENE EXPRESSION ANALYSIS IN Elaeis guineensis DURING INTERACTIONS WITH Hendersonia toruloidea
}

\author{
AMIRAH NOR KAMARUDIN*; IDRIS ABU SEMAN** and ZETTY NORHANA BALIA YUSOF*
}

\begin{abstract}
Thiamine plays an indispensable role as a cofactor in many metabolic reactions in all living organisms. The active form, thiamine pyrophosphate (TPP) functions as a cofactor in important metabolic reactions including glycolysis, pentose phosphate pathway and the tricarboxylic acid cycle. Besides that, thiamine is also associated with the induction of systemic acquired resistance $(S A R)$ in plants. Hendersonia toruloidea is an endophytic fungus originally isolated from oil palm roots which have been shown to have biocontrol activity. Seven months old oil palm seedlings were inoculated with $\mathrm{H}$. toruloidea and the response on the expression of thiamine biosynthesis genes were investigated. Microscopy analysis was performed to visualise the colonisation of the fungus. Ribonucleic acid (RNA) was extracted from oil palm leaves at Day 1, 7, 15 and 30 post-treatment. Quantitative Real-time PCR ( $q R T-P C R$ ) was performed to measure the level of expression of four key thiamine biosynthesis genes, namely THI4, THIC, TH1 and TPK. The results showed up to 12-fold increase in the expression of all gene transcripts at Day 1 and 7 post-treatment. This work provides first evidence of enhancement of thiamine biosynthesis by endophytic colonisation in oil palm seedlings.
\end{abstract}

Keywords: oil palm, endophytic fungus, thiamine biosynthesis, gene expression.

Date received: 4 February 2017; Sent for revision: 15 March 2017; Received in final form: 30 April 2017; Accepted: 3 May 2017.

\section{INTRODUCTION}

Thiamine (vitamin B1), in its active form of thiamine diphosphate is essential cofactor for key enzymes of central metabolism in cellular organisms. It is synthesised de novo only in plants, bacteria and fungi. The thiamine biosynthesis pathway in plants as shown in Figure 1 consists of two separate branches, which is the synthesis of thiazole and pyrimidine moieties. The condensation

* Department of Biochemistry, Faculty of Biotechnology and Biomolecular Sciences,

Universiti Putra Malaysia, 43400 UPM Serdang,

Selangor, Malaysia.

E-mail: zettynorhana@upm.edu.my

** Malaysian Palm Oil Board, 6 Persiaran Institusi,

Bandar Baru Bangi, 43000 Kajang,

Selangor, Malaysia. of pyrimidine and thiazole ring moieties will form thiamine monophosphate, which is then converted to the active form thiamine pyrophosphate (TPP). TPP is a cofactor of pyruvate dehydrogenase which participates in the oxidative decarboxylation of pyruvate to acetyl-CoA, synthesis of amino acid such as valine, leucine and isolecucine, 2-oxoglutarate dehydrogenase which is involved in Krebs cycle (Goyer, 2010; Goyer and Haynes, 2011; Tunc-Ozdemir et al., 2009). TPP is also a cofactor for transketolase in the oxidative pentose phosphate pathway, which plays a role in the production of reactive oxidative species (ROS). Downstream reactions of TPP-dependent of Krebs cycle is the oxidative phosphorylation pathway where electron is generated to synthesise ATP, which is important in energy production in all living organisms. Fundamentally, thiamine forms an indispensable role in proper functioning in plants. 
Apart from its role as an enzymatic cofactor, previous studies had shown that thiamine has noncofactor roles. Thiamine metabolism is involved in plant adaptation towards biotic and abiotic stress in plant and also microorganism (Rapala-Kozik et al., 2012; Sylvander et al., 2013). Specifically, exogenous application of thiamine was reported to confer resistance against biotic stress and abiotic stress (Ahn et al., 2007; Tunc-Ozdemir et al., 2009). Application of thiamine in plants have been shown to activate plant defence responses in Arabidopsis (Ahn et al., 2007). Furthermore, thiamine treatment in soyabean also enhances resistance to charcoal rot disease (Monaim, 2011), rice against sheath blight disease (Bahuguna et al., 2012), and grapevine against a disease caused by Plasmapora viticola (Boubakri et al., 2012). In Arabidopsis thaliana, thiamine treatment activated pathogenesisrelated protein (PR-1) and phenylalanine lyase (PAL) (Ahn et al., 2007). Similarly, thiamine treatment in grapevine reduced downy mildew development compared to untreated control in a dose-dependent manner by inducing hydrogen peroxide generation, callose disposition and host resistance (HR) cell death (Boubakri et al., 2012). Therefore, thiamine is involved in priming, which is important to mitigate any crop-damaging diseases and stresses. Recent studies in oil palm have also shown that the infection of $G$. boninense in oil palm upregulated the expression of the first two enzymes in thiamine biosynthesis pathway (Balia Yusof et al., 2015). Various abiotic stresses have also showed to increase the expression of thiamine biosynthesis genes in oil palm (Abidin et al., 2016). Wong et al. (2016) also reported that there was an increase of up to two-fold in thiamine biosynthesis gene expression when subjected to salinity stress induced by polyethylene glycol (PEG) in oil palm.

Oil palm is the most profitable oil-bearing crops in the world. However, productivity of oil palm is threatened by basal stem rot disease caused by Ganoderma boninense that resulted in major economic losses and yield gap (Barcelos et al., 2015). Therefore, studies on the proper management of the disease have been accelerating. Endophytes, defined as fungi that are present in most plant tissues without causing any visible symptoms were utilised as a biological control agent as a preventive measure against the disease (Wilson, 1995). Several endophytic species have been utilised as a biological control agent namely Actinomycetes, Pseudomonads, Trichoderma and Hendersonia (Sundram et al., 2011). It was reported that the application of the endophytes has growth promoting effects besides disease suppression against $G$. boninense. The endophytic fungus Hendersonia toruloidea, originally isolated from oil palm trunk and root tissues is used as a biocontrol agent. In vitro and nursery trial studies of application of $H$. toruloidea suppressed the infection of pathogenic fungus G. boninense on oil palm (Idris et al., 2012; Nurrashyeda et al., 2011).

Although endophytes generally do not cause visible symptoms, they certainly affect the plant phenotype (Heil, 2011). Recent works demonstrated that fungal endophytes trigger the production of secondary metabolites such as alkaloids, steroids, terpenoids, quinones and phenylpropanoids which act as anti-microbial compounds (Mousa and Raizada, 2013). The production of secondary metabolites therefore increases plant's metabolic fitness and immunity. Since thiamine is associated in its role in plants immunity, the aim of this study is to investigate the response of oil palm seedlings, specifically on the expression of thiamine biosynthesis genes upon colonisation of the endophytic fungus $H$. toruloidea. The morphology and the colonisation pattern of the endophytic $H$. toruloidea was visualised on scanning electron microscopy and transmission electron microscopy.
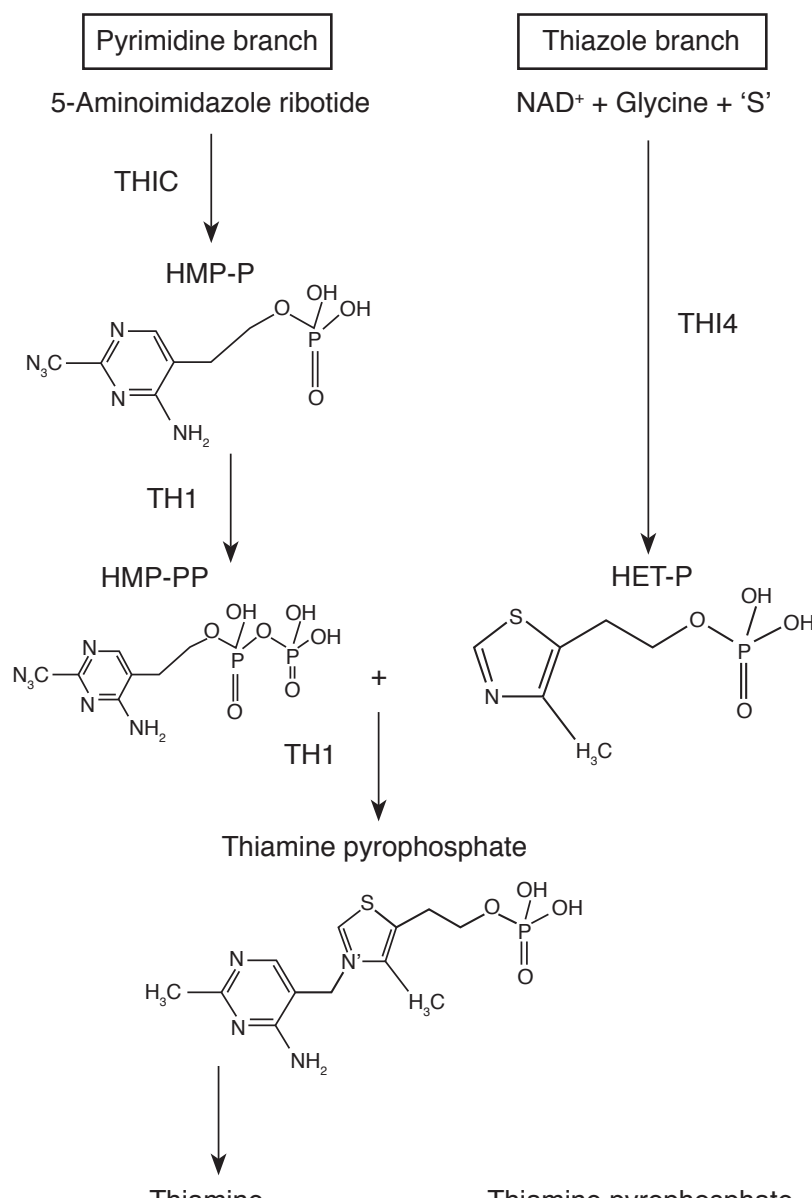

TPK

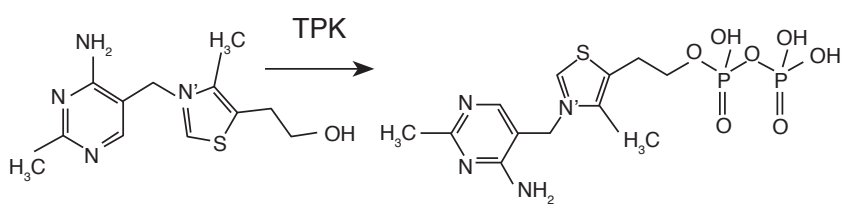

Source: Adapted from Guan et al. (2014).

Figure 1. The thiamine biosynthesis pathway in plants. 


\section{MATERIALS AND METHODS}

\section{Fungal Strains, Growth Conditions and Granular Bioformulation Preparation}

The fungal strain was the endophytic $H$. toruloidea that was previously isolated from healthy oil palm in disease affected areas of MPOB Teluk Intan, Perak, Malaysia (Nur Rashyeda and Idris, 2013). Pure axenic cultures were sub-cultured on potato dextrose agar and incubated at $28^{\circ} \mathrm{C}$ for 10 days. The conidial spores were scraped and poured into potato dextrose broth containing 9\% jaggery. The fungal cultures were incubated at $28^{\circ} \mathrm{C}$ for four days at $150 \mathrm{rpm}$ in a shaking incubator. The fungal cultures were encapsulated in an alginate formulation containing kaolin, empty fruit bunch and pectin (Idris et al., 2010; 2012; Nur Rashyeda et al., 2011).

\section{Application of H. toruloidea to Oil Palm Seedlings}

Seven months old seedlings of Dura $x$ Pisifera $(\mathrm{D} \times \mathrm{P})$ variety of oil palm were grown under nursery conditions at MPOB Nursery, Section 15, Bandar Baru Bangi, Selangor, Malaysia. The oil palm was inoculated with $\mathrm{H}$. toruloidea by applying $50 \mathrm{~g}$ of the bioformulation $\left(10^{7} \mathrm{CFU} \mathrm{g}^{-1}\right)$ and drenched with tap water. Control plants were not treated. Sampling of spear leaves and roots was carried out at 0, 1, 7, 15 , and 30 days post-treatment with three replicates for each time point. The tissue samples were frozen in liquid nitrogen and stored at $-80^{\circ} \mathrm{C}$ until further analysis.

\section{Reisolation of Endophytic Fungus by Direct Plating Technique}

To confirm the presence of $H$. toruloidea in the seedlings, the endophytic fungus was reisolated from the surface-sterilised roots and placed on potato dextrose agar according to the procedure described by Idris et al. (2010). The $10 \mathrm{~cm}$ root segments were cut and dipped into 10\% Clorox for 2 $\mathrm{min}$. The root segments were then dipped into $70 \%$ alcohol for $1 \mathrm{~min}$, followed by washing in sterile distilled water twice for $1 \mathrm{~min}$. The root segments were scraped to reveal inner layer, cut into $5 \mathrm{~mm}$ pieces, and plated on potato dextrose agar. The agar was incubated at $28^{\circ} \mathrm{C}$ for seven to 10 days. The physical and morphological structures were examined and confirmed.

\section{Scanning Electron Microscopy Analysis}

To further illustrate the morphology of endophytic $H$. toruloidea, root segments were processed for scanning electron microscopy. Briefly, root samples were soaked in $4 \%$ glutaraldehyde solution overnight. The root samples were put in dehydration series of $(25 \%, 50 \%, 75 \%, 90 \%, 100 \%)$. Samples were then dried using critical point drying. Each specimen was mounted on aluminium stubs, coated with gold in a sputter, and observed in scanning electron microscopy.

\section{Transmission Electron Microscopy Analysis}

Oil palm root sections were cut into $1 \mathrm{~mm}^{3}$ pieces. The root sections were put into separate vials and fixed in fixative $4 \%$ glutaraldehyde for two days. Next, the root sections were washed with $0.1 \mathrm{M}$ sodium cacodylate buffer for three changes of $30 \mathrm{~min}$ each. The sections were then post-fixed in $1 \%$ osmium tetroxide for $2 \mathrm{hr}$ at $4^{\circ} \mathrm{C}$ and washed again with 0.1 sodium cacodylate buffer for three changes of $30 \mathrm{~min}$ each. A dehydration series of acetone 35\%, 50\%, 75\%, 95\% was performed for 45 min each series. Final dehydration series of $100 \%$ acetone was performed for three changes of $1 \mathrm{hr}$ each. Further steps of processing include infiltration of the specimen with acetone and resin mixture as follows:

\begin{tabular}{ccc}
\hline Acetone & Resin & Duration (hr) \\
\hline 1 & 1 & 12 \\
1 & 3 & 12 \\
& $100 \%$ & 12 \\
& $100 \%$ & 4 \\
\hline
\end{tabular}

The specimen was then embedded into beam capsules and filled with resin mixture. It was polymerised in oven at $60^{\circ} \mathrm{C}$ for $48 \mathrm{hr}$. A thick sectioning was performed by cutting the polymerised specimen using an ultramicrotome to cut $1 \mu \mathrm{m}$ thick sections. The thick sections were stained with toluidine blue, dried on a hot plate. The stain was washed under running tap water. The area of interest was examined under light microscope. For the ultrathin sectioning, the ultrathin sections were cut and selected for silver sections. The sections were selected with a grid and dried using filter paper. For the staining procedure, the sections were stained with uranyl acetate for $15 \mathrm{~min}$ and washed with double distilled water. Next, the sections were stained with lead stain for $10 \mathrm{~min}$ and washed with double distilled water. Lastly, the sections were viewed using transmission electron microscopy.

\section{RNA Isolation and Quantitative Real-time Polymerase Chain Reaction (qRT-PCR) Analysis}

Total ribonucleic acid (RNA) was isolated from oil palm spear leaves according to CTAB method with modifications (Zeng and Yang, 2002). Genomic DNA was removed using DNase I (Promega, USA). One $\mu \mathrm{g}$ of purified RNA samples were reverse transcribed using GoScript cDNA 
synthesis kit (Promega, USA).The specific primers for qRT-PCR were designed by Primer Premier 6.0 (Primer Biosoft, Palo Alto, CA, USA). In a $10 \mu \mathrm{l}$ PCR reaction mixture, $4.0 \mu \mathrm{l}$ of cDNA template, $5 \mu \mathrm{l}$ of 2 X SYBR SensiFast Hi-Rox (Bioline), $0.4 \mu \mathrm{l}$ of 10 $\mathrm{mM}$ of forward and reverse primers for each gene. The qRT-PCR was performed using Bio-Rad CFX Connect 96. The cycling conditions used was $2 \mathrm{~min}$ at $95^{\circ} \mathrm{C}$, followed by 40 cycles of $10 \mathrm{~s}$ at $95^{\circ} \mathrm{C}$, and $30 \mathrm{~s}$ at $60^{\circ} \mathrm{C}$. Three biological replicates with three technical replicates each were assayed for each sample.

\section{Analysis of Gene Expression}

Transcript levels of each gene were normalised to reference genes tubulin, and glyceraldehyde-3phosphate using the method by (Vandesompele et al., 2002). The $2^{-\triangle \Delta C T}$ method was used to analyse the relative changes in gene expression of THI4, THIC, TPK and TH1 (Livak and Schmittgen, 2001).

\section{DNA Sequencing}

Purified PCR products were sequenced using $1^{\text {st }}$ BASE DNA sequencing service $\left(1^{\text {st }}\right.$ BASE,
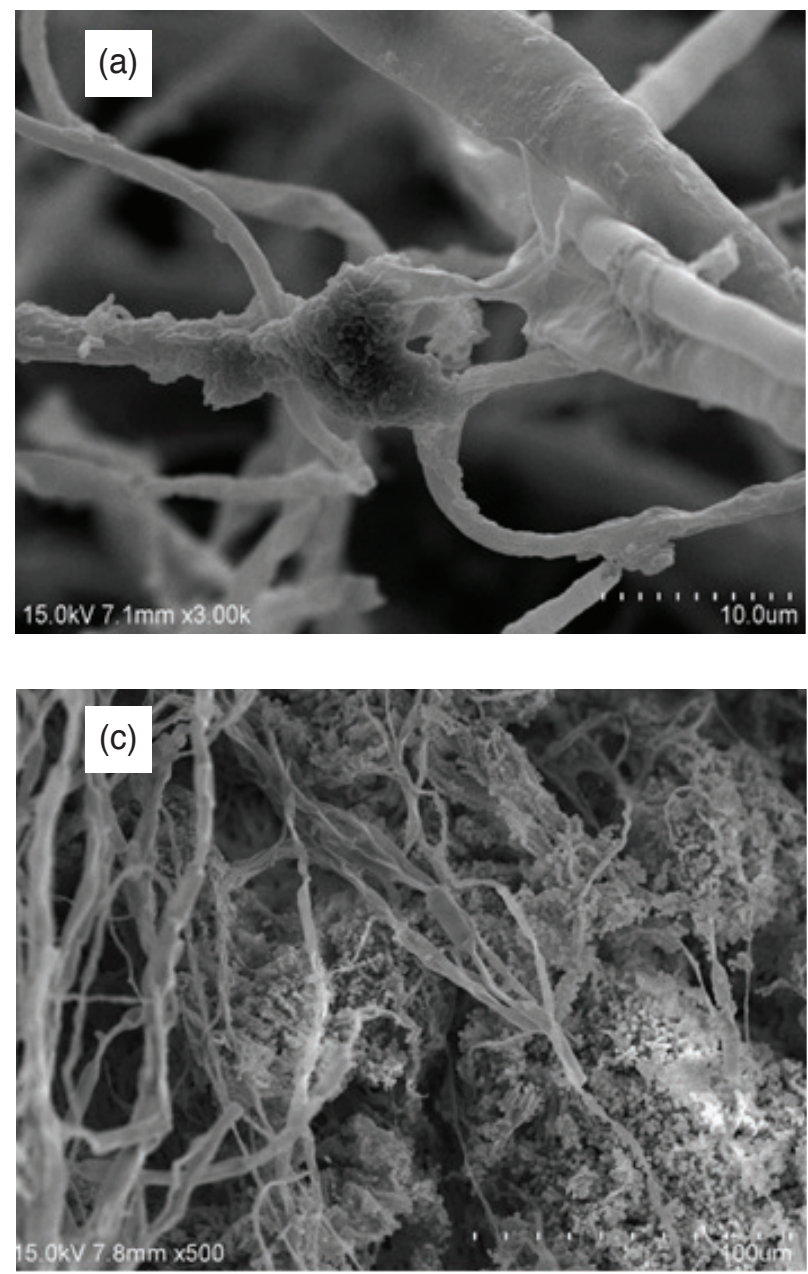

Singapore). The FASTA sequences were then analysed using Basic Local Alignment Search Tool (BLAST) (https://blast.ncbi.nlm.nih.gov) to find DNA sequences in NCBI database.

\section{RESULTS AND DISCUSSION}

\section{Colonisation of Endophytic H. toruloidea in Oil Palm Seedlings}

The colonisation ability of the fungus was evaluated by culture dependent method of direct plating technique to re-isolate the fungus into a potato dextrose agar. After 10 days of incubation on potato dextrose agar plate, the endophytic fungus was successfully recovered, revealing the characteristics of greyish-black mycelia on the root sections. The root sections that was sent for scanning electron microscopy analysis also revealed hyphae, conidial spores and ascospores which are sac-contained spores which confirmed the identity of the fungus (Figure 2). Further evaluation of the colonisation ability of $H$. toruloidea involved transmission electron microscopy analyses to
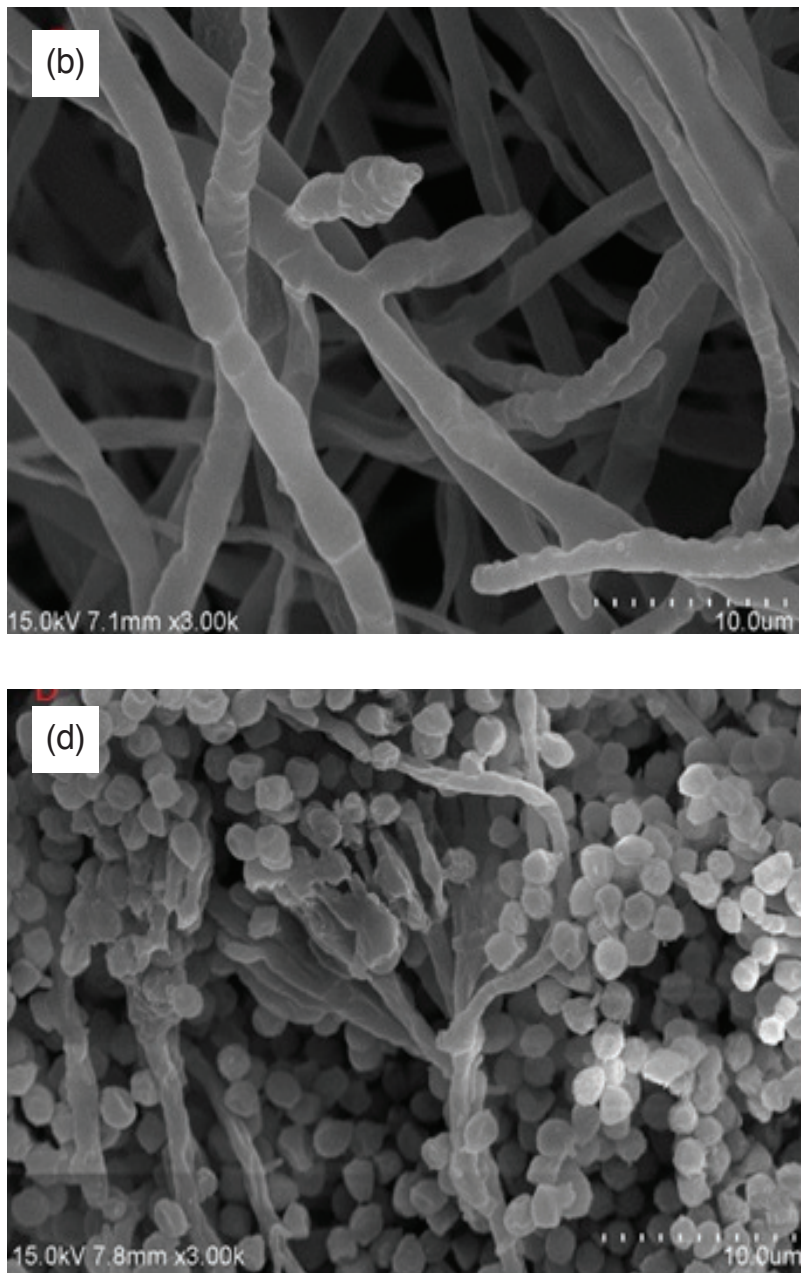

Figure 2. The morphological structures of $\mathrm{H}$. toruloidea viewed via scanning electron microscopy analysis. (a) and (b) Are the hyphae structures. (c) Ascospores structures. (d) Conidial spores. 
visualise the colonisation and localisation of the fungus inside the root. Figure 3 reveals transverse section of oil palm root at Day 1 and Day 30 postcolonisation. $H$. toruloidea was found to be residing mostly in the intracellular cells of the cortical tissues.

The Effect of Colonisation of $H$. toruloidea on Expression of Thiamine Biosynthesis Genes in Oil Palm

In this study, the key thiamine biosynthesis genes in oil palm namely THIC, THI4, TH1 and TPK were identified and sequenced. All primers were designed between 100-200 bp for efficient amplification and quantification (Table 1). The expression of thiamine biosynthesis genes in oil palm seedlings during colonisation of endophytic $H$. toruloidea was performed using qRT-PCR at different time points of $24 \mathrm{hr}, 7-, 15$ - and 30-day posttreatment. After $24 \mathrm{hr}$ of application of H. toruloidea, the oil palm seedlings showed a significantly increased expression of THI4, TPK, THIC, TH1 (12.9fold, 3.65-fold, 1.65-fold, 3.047-fold respectively).
Meanwhile at Day 7, THI4, TPK, THIC, TH1 were shown to be downregulated (2.85-fold, 0.92-fold, 0.44 and 1.07-fold respectively). After two weeks and four weeks of endophytic treatment, the level expressions of THI4, TPK, THIC and TH1 decreased lower than control seedlings, which was normalised to 1.

The hypothesis of the study is that the thiamine biosynthesis genes will be upregulated upon endophytic colonisation. Successful colonisation of $H$. toruloidea was visualised by transmission electron microscopy analysis which revealed that the fungus resided in intracellular tissues as shown in Figure 3. Overall, THI4, TPK, THIC, and TH1 were upregulated after $24 \mathrm{hr}$ of inoculation as shown in Figure 4. Previous studies have shown that thiamine and its intermediates are involved in systemic acquired resistance in various plant species and acts as a signalling molecule (Rapala-Kozik et al., 2008; Tunc-Ozdemir et al., 2009). The observation of upregulation of thiamine biosynthesis genes as a result of colonisation of endophytic fungus is relatively novel.

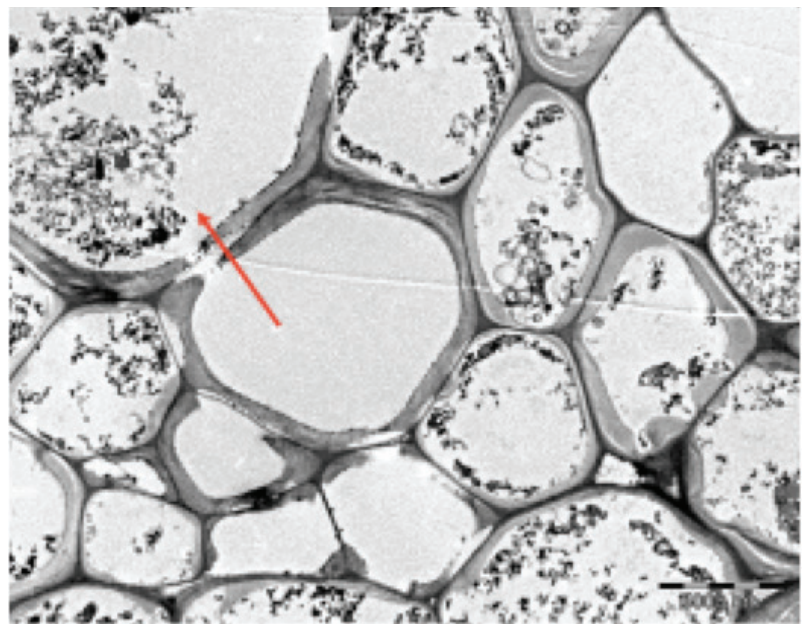

Figure 3. Transverse sections of oil palm root colonised by $\mathrm{H}$. toruloidea viewed via transmission electron microscopy analysis. Red arrows showing hyphae and spores colonising intracellular cells at Day 30 of colonisation.

TABLE 1. LIST OF PRIMERS USED IN THIS STUDY

\begin{tabular}{|c|c|c|c|}
\hline Primer name & Forward $\left(5^{\prime}\right.$ to $\left.3^{\prime}\right)$ & Reverse ( $5^{\prime}$ to $\left.3^{\prime}\right)$ & Amplicon size (bp) \\
\hline $\begin{array}{l}\text { Tubulin } \\
\text { F3 R3 }\end{array}$ & ACACGGCATAGATCCAACCG & TGG TTC CAG GCT CCA AATC & 147 \\
\hline $\begin{array}{l}\text { GADPH } \\
\text { F1 R1 }\end{array}$ & GTCCCACCTGCTCAAGTACG & CGGACACGACCTTGATGACC & 110 \\
\hline $\begin{array}{l}\text { THI4 } \\
\text { F3 R3 }\end{array}$ & ATGATCACCCACGCCGACAC & TGCTCCACGATGGCGACTTG & 104 \\
\hline $\begin{array}{l}\text { THIC } \\
\text { F3 R3 }\end{array}$ & AATGAAGGTCCAGGGCAT & GCTGAGGTGATGTGATCA & 188 \\
\hline $\begin{array}{l}\text { TH1 } \\
\text { F5 R5 }\end{array}$ & CCGACATGCCAGCACGAGTT & ACACCACCACAGCCAATGTAGT & 130 \\
\hline $\begin{array}{l}\text { TPK } \\
\text { F5 R5 }\end{array}$ & GGGAGCACTTGGTGGAAGGTTT & TGTGGATCTCATGGCGATGTGT & 140 \\
\hline
\end{tabular}



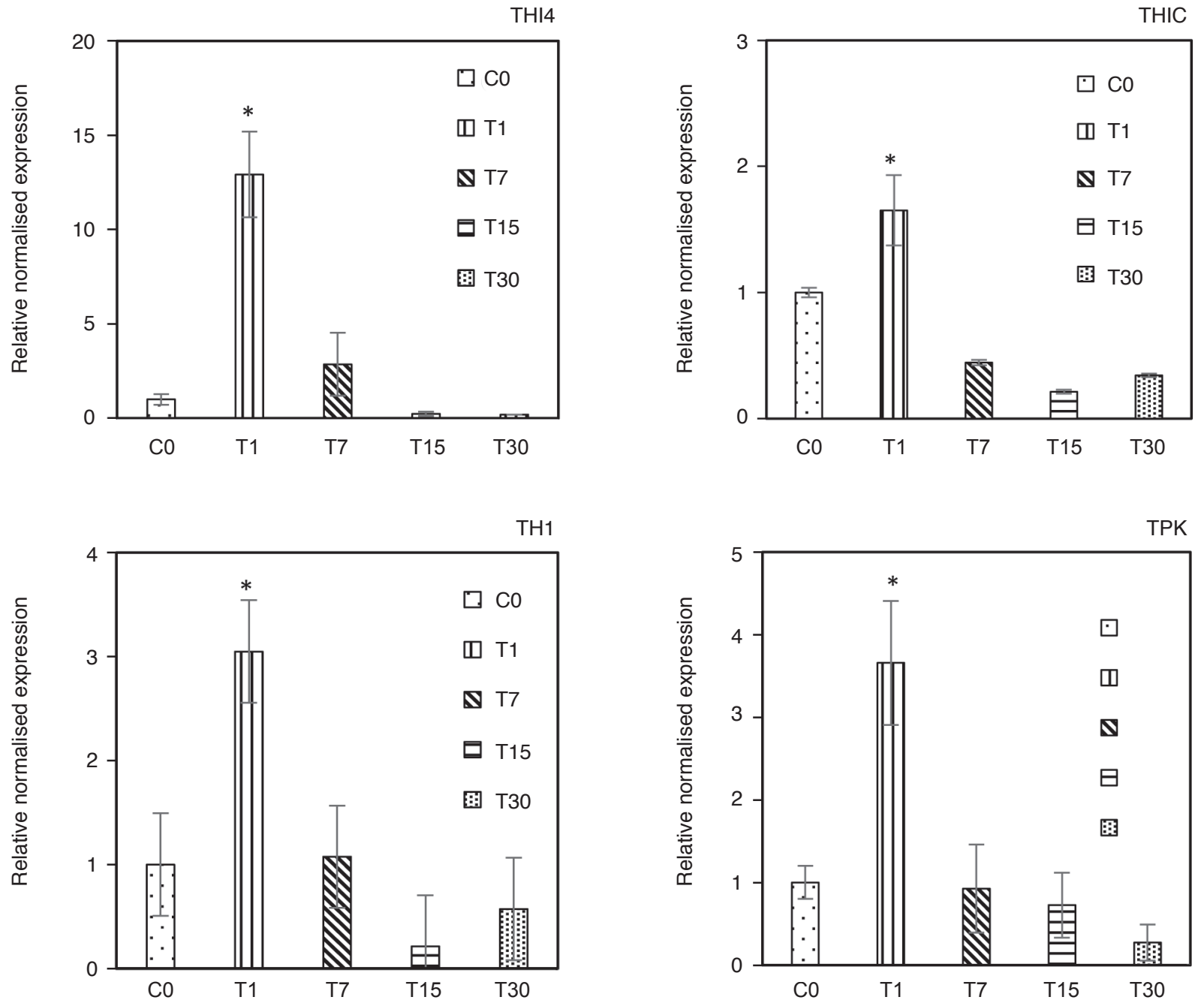

Figure 4. The effect of colonisation of H. toruloidea on the expression of THI4, THIC, TH1, and TPK. C0: control Day 0, T1: H.t inoculated Day 1, T7: H.t-inoculated Day 7, T15: H.t-inoculated Day 15, T30: H.t-inoculated Day 30. Error bars indicate SE between three biological replicates. Asterisks indicate significant difference when compared to control using Student T-test, $(p<0.05)$.

It was observed that the level of expression of THI4, which is the first enzyme in the thiamine biosynthesis pathway of the thiazole branch was remarkably high upon $24 \mathrm{hr}$ of endophytic colonisation by $H$. toruloidea, which was about $12-$ fold. Because of the relatively long duration of observation, the effects of endophytic colonisation, the downregulation of thiamine biosynthesis genes after seven days of inoculation was due to adaptation to the establishment of the $H$. toruloidea in the oil palm seedlings. The level of expression of TH1, TPK and THIC was not prominent compared to THI4. This suggest that THI4, which is the thiazole synthase is involved in stress responses. In fungal pathogen Verticilium dahlia, VdTHI4, which was found to be localised in the mitochondria is required for stress tolerance (Hoppenau et al., 2014).

It was implied that the upregulation of thiamine biosynthesis genes specifically through the increase of expression of THI4 was caused by the increased demand of TPP which acts as coenzymes in numerous physiological processes notably glycolysis, pentose phosphate pathway, synthesis of nucleic acid and synthesis of NADH. The increased requirement of the TPP-dependent enzymes was probably due to perturbations in the metabolism to deal with stress and adaptive responses due to $H$. toruloidea inoculation in the oil palm seedlings (Rapala-Kozik et al., 2008).

The application of endophyte is an excellent strategy to activate systemic acquired resistance in plants. Numerous studies have highlighted that potential role of fungal endophytes in plant protection through the upregulation of secondary metabolites namely phytohormones, phenolic compounds, and defence enzymes (Gao et al., 2010; Kumara et al., 2014). Endophyte-mediated systemic acquired resistance could serve as disease control strategies to develop plants with enhanced disease 
resistance. The relationship between thiamine and systemic acquired resistance was established by Ahn et al. (2007) in which thiamine treatment elicited transient expression of pathogenesisrelated (PR) genes and hypersensitive responses in rice, Arabidopsis and cucumber. Similarly, thiamine treatment in rice induced priming, which resulted in higher hydrogen peroxide content, total phenolics accumulation and phenylalanine-lyase activity (Bahuguna et al., 2012). Meanwhile, the pathogenic fungus Sclerotinia inoculated on Arabidopsis upregulated thiamine biosynthesis and correlated with increased accumulation of thiamine, thiamine monophosphate, and thiamine pyrophosphate (Zhou et al., 2013). This implies that there is an increase in de novo synthesis of endogenous thiamine upon Sclerotinia infection. Thiamine-treated plant confers plant resistance to the pathogenic fungus by producing reactive oxidative species (ROS) to promote defence-signalling. Therefore, in relation to this study, it can be safely implicated that thiamine biosynthesis, specifically the upregulation of THI4 was due to early adaptive defence responses in the oil palm seedlings upon active colonisation of $H$. toruloidea, as confirmed by scanning electron microscopy and re-isolation studies.

Ideally, it is a minimal requirement that both THIC and THI4, the upstream enzymes on both branches of pyrimidine and thiazole have to be upregulated to increase the total thiamine pool (Dong et al., 2016; Pourcel et al., 2013). It was shown that THI4 was significantly upregulated to 12.9-fold after $24 \mathrm{hr}$ of endophytic colonisation. Meanwhile, the increased level of expression of THIC upon colonisation of endophytic fungus is not as prominent which is about 1.65-fold. This can be explained as THIC is a highly complex energy-expensive enzyme. The synthesis of THIC requires a big energy investment as structural studies have shown that THIC is a highly complex enzyme, as it is made of an iron-sulphur cluster, S-adenosyl methionine and ferredoxin-thioredoxin redox system (Colinas and Fitzpatrick, 2015). The compound is also involved in oxygenic photosynthesis and is regulated according to the circadian rhythm (Colinas and Fitzpatrick, 2015).

Apart from that, THIC which is responsible for synthesis of HMP-PP (hydroxymethylpyrimidinepyrophosphate), is required for synthesis of TMP by condensation between HMP-PP and HET-P. The unbalanced magnitude of expression of THIC and THI4 could be explained by involvement of other sources of HMP-PP. In yeast (Saccharomyces cerevisiae) thiamine biosynthesis pathway, HMP$\mathrm{PP}$ is obtained from pyridoxal 5-phosphate (PLP) biosynthesis pathway (Li et al., 2010). This implies that THIC is not significantly upregulated if HMPPP pool is already sufficient.
It is interesting to note that after seven days and 15 days post-inoculation, the expression of thiamine biosynthesis genes is lower in inoculated seedlings than control seedlings. This suggests tight regulatory processes, where the genes are switched off when thiamine pool is already sufficient. It also implicates that the endophytic fungus $H$. toruloidea also synthesises thiamine, therefore, thiamine biosynthesis machinery in oil palm are repressed. Although plants generally biosynthesise thiamine, it may be more advantageous to obtain from various external sources through biotic interactions (Helliwell et al., 2014). Paerl et al. (2015) reported that during co-culturing of auxotrophic picoeukaryotic algae Ostreococcus lucimarinus and bacterium Pseudoalteromonas sp, the algae was able to salvage thiamine from the bacterium.

\section{CONCLUSION}

The major findings presented here showed that successful colonisation by $H$. toruloidea in oil palm seedlings resulted in upregulation of thiamine biosynthesis genes. The attenuation in thiamine biosynthesis signals adaptation, which may be important to maintain optimum growth and function in plants. Further molecular, biochemical and physiological studies are needed to understand the roles and functions of thiamine in oil palm stress protection.

\section{ACKNOWLEDGEMENT}

This work was carried out with the support of MPOB and also Fundamental Research Grant Scheme (FRGS) from the Ministry of Higher Education, Malaysia (Project No. 5524589).

\section{REFERENCES}

ABIDIN, A A Z; YEE, W S; ABDUL RAHMAN, N S; CHE IDRIS, Z H and BALIA YUSOF, Z N (2016). Osmotic, oxidative and salinity stresses upregulate the expressions of thiamine (vitamin B1) biosynthesis genes (THIC and THI1/THI4) in oil palm (Elaeis guineensis). J. Oil Palm Res. Vol. 28(3): 308-319.

AHN, I P; KIM, S; LEE, Y H and SUH, S C (2007). Vitamin B1-induced priming is dependent on hydrogen peroxide and the NPR1 gene in Arabidopsis. Plant Physiology, 143: 838-848.

BAHUGUNA, R N; JOSHI, R;SHUKLA, A; PANDEY, $\mathrm{M}$ and KUMAR, J (2012). Thiamine primed defense provides reliable alternative to systemic fungicide carbendazim against sheath blight disease in rice 
(Oryza sativa L.). Plant Physioliology Biochemistry, 57: 159-167.

BALIA YUSOF, Z N; BORHAN, F P; MOHAMAD, F A and RUSLI, M H (2015). The effect of Ganoderma boninense infection on the expressions of thiamine (vitamin B1) biosynthesis genes in oil palm. J. Oil Palm Res. Vol. 27: 12-18.

BARCELOS, E; RIOS, S D E A; CUNHA, R N V; LOPES, R; MOTOIKE, S Y and BABIYCHUK, E (2015). Oil palm natural diversity and the potential for yield improvement. Frontiers in Plant Science, 6: 190.

BOUBAKRI, H; WAHAB, $\mathrm{M}$ A; CHONG, J; BERTSCH, C; MLIKI, A and SOUSTREGACOUGNOLLE, I (2012). Thiamine induced resistance to Plasmopara viticola in grapevine and elicited host-defense responses, including HR likecell death. Plant Physioliology Biochemistry, 57: 120133.

COLINAS, $\mathrm{M}$ and FITZPATRICK, T B (2015). Natures balancing act: examining biosynthesis de novo, recycling and processing damaged vitamin B metabolites. Current Opinion Plant Biology, 25: 98106.

DONG, W; THOMAS, N; RONALD, PC and GOYER, A (2016). Overexpression of thiamin biosynthesis genes in rice increases leaf and unpolished grain thiamin content but not resistance to Xanthomonas oryzae pv. oryzae. Frontiers in Plant Science, 7: 1-11.

GAO, F K; DAI, C C and LIU, XZ (2010). Mechanisms of fungal endophytes in plant protection against pathogens. African J. Microbiology Research, 4: 13461351.

GOYER, A (2010). Thiamine in plants: aspects of its metabolism and functions. Phytochemistry, 71: 16151624.

GOYER, A and HAYNES, K G (2011). Vitamin B1 content in potato: effect of genotype, tuber enlargement, and storage, and estimation of stability and broad-sense heritability. American J. Potato Research, 88: 374-385.

GUAN, J; HASNAIN, G; GARRETT, T J; CHASE, C D; GREGORY, J and HANSON, AD (2014). Divisions of labor in the thiamin biosynthetic pathway among organs of maize. Frontiers in Plant Science, 5: 1-11.

HEIL, M (2011). The microbe-free plant: fact or artifact. Biological Nitrogen Fixation. p. 1163-1174.

HELLIWELL, $\mathrm{K}$ E; SCAIFE, $\mathrm{M}$ A; SASSO, S; ARAUJO, A P U; PURTON, S and SMITH, A G
(2014). Unraveling vitamin B12-responsive gene regulation in algae. Plant Physiology, 165: 388-397.

HOPPENAU, C E; TRAN, V T; KUSCH, H; AßHAUER, K P; LANDESFEIND, M; MEINICKE, $P$ and BRAUS, G H (2014). Verticillium dahliae VdTHI4, involved in thiazole biosynthesis, stress response and DNA repair functions, is required for vascular disease induction in tomato. Environmental and Experimental Botany, 108: 14-22.

IDRIS, A S; NOOR HAIDA, S and NUR RASHYEDA, R (2010). GanoEF1 - a fungal biocontrol agent for Ganoderma in oil palm. MPOB Information Series No. 501: 1-4.

IDRIS, A S; NURRASHYEDA, R; MAIZATUL, S M; MADIHAH, A Z; AHMAD TARMIZI, M; KUSHAIRI, D; WAN AZHA, W $\mathrm{M}$ and TONY PENG, S H (2012). Biofertiliser Hendersonia GanoEF as biological control of Ganoderma in oil palm, $M P O B$ Information Series No. 595: 1-4.

KUMARA, PM; SHWETA, S; VASANTHAKUMARI, M M; SACHIN, N; MANJUNATHA, B L; JADHAV, S S., RAVIKANTH, G; GANEISHAIAH, K N and SHAANKER, R U (2014). Endophytes and plant secondary metabolite synthesis: molecular and evolutionary perspective. Advances in Endophytic Research. p. 177-190.

LI, M; PETTEYS, B J; MCCLURE, J M; VALSAKUMAR, V; BEKIRANOV, S; FRANK, E L and SMITH, J S (2010). Thiamine biosynthesis in Saccharomyces cerevisiae is regulated by the $\mathrm{NAD}^{+}$dependent histone deacetylase Hst1. Molecular and Cellular Biology, 30: 3329-41.

LIVAK, K J and SCHMITTGEN, T D (2001). Analysis of relative gene expression data using real-time quantitative PCR and the $2^{-\triangle \Delta C T}$ method. Methods, 25: 402-408.

MONAIM, M F A (2011). Role of riboflavin and thiamine in induced resistance against charcoal rot disease of soybean. African J. Biotechnology, 10: 10842-10855.

MOUSA, W K and RAIZADA, M N (2013). The diversity of anti-microbial secondary metabolites produced by fungal endophytes: an interdisciplinary perspective. Frontiers in Microbiology, 4: 65.

NUR RASHYEDA, R; IDRIS, A S; MADIHAH, A Z; RAMLE, M and KUSHAIRI, A (2011). Hendersonia GanoEF1 granules for the control of Ganoderma boninense in oil palm. MPOB Information Series No. 556: $1-4$. 
NUR RASHYEDA, R and IDRIS, AS (2013). GanoEF1 biofertiliser-colonization of Hendersonia GanoEF1 in oil palm roots. Paper presented at the Fifth International Seminar: Sustainable Management of Pests and Diseases in Oil Palm - The Way Forward.

PAERL, R W; BERTRAND, E M; ALLEN, A E; PALENIK, B and AZAM, F (2015). Vitamin B1 ecophysiology of marine picoeukaryotic algae: strain-specific differences and a new role for bacteria in vitamin cycling. Limnology and Oceanography, 60: 215-228.

POURCEL, L; MOULIN, $\mathrm{M}$ and FITZPATRICK, T B (2013). Examining strategies to facilitate vitamin B1 biofortification of plants by genetic engineering. Frontiers in Plant Sciences, 4: 160.

RAPALA-KOZIK, M; KOWALSKA, E and OSTRWOSKA, K (2008). Modulation of thiamine metabolism in Zea mays seedlings under conditions of abiotic stress. J. Experimental Botany, 59: 4133-4143.

RAPALA-KOZIK, M; WOLAK, N; KUJDA, M and BANAS, A K (2012). The upregulation of thiamine (vitamin B1) biosynthesis in Arabidopsis thaliana seedlings under salt and osmotic stress conditions is mediated by abscisic acid at the early stages of this stress response. BioMed Central Plant Biology, 12: 2.

SUNDRAM, S; MEON, S; SEMAN, I A and OTHMAN, R (2011). Symbiotic interaction of endophytic bacteria with arbuscular mycorrhizal fungi and its antagonistic effect on Ganoderma boninense. J. Microbiology, 49: 551-557.
SYLVANDER, P; HÄUBNER, N and SNOEIJS, P (2013). The thiamine content of phytoplankton cells is affected by abiotic stress and growth rate. Microbial Ecology, 65: 566-577.

TUNC-OZDEMIR, M; MILLER, G; SONG, L; KIM, J; SODEK, A; KOUSSEVITZKY, S; MISRA, A N; MITTLER, R and SHINTANI D (2009). Thiamin confers enhanced tolerance to oxidative stress in Arabidopsis. Plant Physiology, 151: 421-32.

VANDESOMPELE, J; DE PRETER, K; PATTYN, F; POPPE, B; VAN ROY, N; DE PAEPE, A and SPELEMAN, F (2002). Accurate normalization of real-time quantitative RT-PCR data by geometric averaging of multiple internal control genes. Genome Biology, 3: 7.

WILSON, D (1995). Endophyte: the evolution of a term, and clarification of its use and definition. Oikos, 73(2): 274-276.

WONG, S Y; ABDUL AZIZ, S D; and BALIA YUSOF, Z N (2016). Osmotic stress upregulates the transcription of thiamine (vitamin B1) biosynthesis genes (THIC and THI4) in oil palm (Elaeis guineensis). African J. Biotechnology, 15(29): 1566-1574.

ZENG, Y and YANG, T (2002). RNA isolation from highly viscous samples rich in polyphenols and polysaccharides. Plant Molecular Biology Reporter, 20: 417.

ZHOU, J; SUN, A and XING, D (2013). Modulation of cellular redox status by thiamine-activated NADPH oxidase confers Arabidopsis resistance to Sclerotinia sclerotiorum. J. Experimental Botany, 64: 3261-3272. 